\title{
A EFETIVAÇÃO DE DIREITOS SOCIAIS PELA VIA NÃO JUDICIAL
}

\author{
Dissertação de Mestrado. \\ Orientadora: Professora Associada Dra. ANNA CANDIDA DA CUNHA \\ FERRAZ.
}

UNIVERSIDADE DE SÃO PAULO

FACULDADE DE DIREITO

São Paulo - SP 


\section{A EFETIVAÇÃO DE DIREITOS SOCIAIS PELA VIA NÃO JUDICIAL}

Dissertação de Mestrado apresentada à Banca Examinadora do Programa de Pós-Graduação em Direito da Faculdade de Direito da Universidade de São Paulo, como exigência parcial para obtenção do título de Mestre em Direito, na área de concentração Direito do Estado, sob a orientação da Professora Associada Dra. ANNA CANDIDA DA CUNHA FERRAZ.

UNIVERSIDADE DE SÃO PAULO

FACULDADE DE DIREITO

São Paulo - SP

2018 
Curado, Lúcio Mauro Carloni Fleury Curado

A efetivação de direitos sociais pela via não judicial. / Lúcio Mauro Carloni Fleury Curado ; orientadora Anna Candida da Cunha Ferraz. -São Paulo, 2018.

$241 \mathrm{p}$.

Dissertação (Mestrado - Programa de Pós-Graduação em Direito do Estado) - Faculdade de Direito, Universidade de São Paulo, 2018.

1. Direitos sociais. 2. Efetivação coletiva. 3. Via não judicial. 4. Instrumentos de efetivação. 5. Agentes. I. Ferraz, Anna Candida da Cunha, orient. II. Título. 
Lúcio Mauro Carloni Fleury Curado. A efetivação de direitos sociais pela via não judicial. 2018. 241 folhas. Mestrado. Faculdade de Direito, Universidade de São Paulo, São Paulo, 2018.

\section{RESUMO}

Tem tido bastante destaque no debate jurídico contemporâneo a problemática da concretização dos direitos fundamentais sociais, sendo abundantes os textos que, discorrendo acerca do grau de eficácia da norma constitucional que positiva direitos prestacionais ou sobre os contornos da separação de Poderes, se voltam à discussão dos limites de legitimidade da intervenção judicial nessa seara.

O presente estudo busca enfrentar o tema dos direitos sociais sob um viés alternativo, enfocando as possibilidades de atuação não judicial nesse cenário.

Pauta-se o estudo pela compreensão de que o texto constitucional traz um dever geral de busca, no maior grau possível, da implementação dos direitos sociais nele previstos.

Para os atores públicos imbuídos de atuar nesse campo há um dever de atuação intrínseco ao próprio exercício de suas funções, e para seu cumprimento podem fazer uso de variados instrumentos que viabilizam soluções resolutivas independentemente de intermediação judicial.

Para os cidadãos, por outro lado, há um dever fundamental de contribuir para com o objetivo de construção de uma sociedade solidária. Não obstante a atuação aqui se paute em regra pela voluntariedade e por mais ampla liberdade - mas com menor amplitude de instrumentos -, o texto buscará o resgate da noção de que recai também sobre a sociedade, e não apenas sobre 0 Estado por ela criado, o papel de contribuir ativamente para a definição dos rumos da coisa pública.

Resgata-se a solidariedade como valor que não apenas justifica a própria positivação dos direitos sociais, como também impõe difusamente uma responsabilidade por sua consecução, que se faz possível não apenas pela 
atuação estatal mas também, complementarmente, através dos mecanismos abertamente facultados à iniciativa privada.

O trabalho também discutirá os sujeitos passivos da responsabilidade de satisfação de direitos sociais, identificando a possibilidade de demandar o cumprimento de dadas prestações não apenas em face do EstadoAdministração, mas também em face de determinados atores privados.

No curso da apresentação serão trazidos os contornos distintivos das vias extrajudicial e judicial na busca pela efetivação de direitos sociais, com a problematização das dificuldades e dos limites de cada qual.

Nesse trajeto será delineada a ampliação da noção de acesso à justiça para abarcar soluções não judiciais de controvérsias, sendo indicada a evolução, nesse debate, da compreensão acerca dos limites de abordagens consensuais junto à Administração em matéria de direitos coletivos.

A exposição será ilustrada por estudos de casos representativos do alcance possível de atuações não judiciais.

Espera-se contribuir assim para clarear o debate dos direitos sociais, indicando que resultados satisfatórios nesse campo podem vir por variados caminhos, que merecem ser melhor conhecidos.

Direitos sociais - concretização - esfera extrajudicial - instrumentos - atores 
Lúcio Mauro Carloni Fleury Curado. Social rights' non judicial implementation. 2018. 241 pages. Master. Faculty of Law, University of São Paulo, São Paulo, 2018.

\section{ABSTRACT}

The problem of the realization of fundamental social rights has been very prominent in the contemporary legal debate, and are abundant the texts that, discussing the extension of the efficiency of constitutional rules that bring rights to benefits, focus on the limits of the legitimacy of judicial intervention in this area.

The present study lends itself to bringing an alternative approach to the theme, focusing in the possibilities of non-judicial action in this scenario.

The study is based on the understanding that the constitutional text stands a general duty to seek, as far as possible, the implementation of the social rights envisaged in it.

For the public actors imbued with acting in this field there is a duty of action intrinsic to the proper exercise of their functions, and for its fulfillment they may make use of various instruments that enable resolutive solutions regardless of judicial intermediation.

For citizens, on the other hand, there is a fundamental duty to contribute to the goal of building a supportive society. Notwithstanding the fact that as a rule the action here is based on willingness and broader freedom - but with a smaller range of instruments - the text will seek to rescue the notion that it also falls on society, not only on the State it creates, the role to contribute actively to the definition of the directions of the public interest.

Solidarity is rescued as a value that not only justifies the very positivization of social rights, but also imposes a diffuse responsibility for its achievement, which is made possible not only by state action but also, complementarily, through mechanisms openly provided to private initiative.

The paper will also discuss the responsibles for the satisfaction of social rights, identifying the possibility of demanding the fulfillment of benefits not only opposite the State, but also opposite certain private actors. 
In the course of the presentation, the distinctive outlines of extrajudicial and judicial channels in the search for the realization of social rights will be brought forward, with the problematization of the difficulties and the limits of each one.

In this way, it will be shown the expansion of the notion of access to justice to encompass non-judicial dispute resolution, indicating the evolution, in this debate, of the understanding of the limits of consensual approaches along with the Administration in matters of collective rights.

The exposition will be illustrated by case studies and by statistical data representative of the possible reach of non-judicial actions.

It is hoped that this approach will help to clarify the debate on social rights, indicating that satisfactory results in this field can come in different ways, that deserve to be better known.

Social rights - implementation - non judicial arena - instruments - actors 


\section{SUMÁRIO}

Introdução 9

1. Delimitação conceitual e metodológica ………….....................................15

2. O lento caminho da positivação à efetivação de direitos sociais........................25

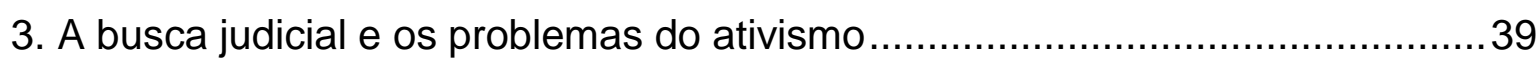

4. A reformulação da noção de acesso à justiça.................................................51

4.1. O fomento aos meios alternativos e o sistema multiportas ........................60

4.2. A disseminação do discurso jurídico e a interpretação aberta da

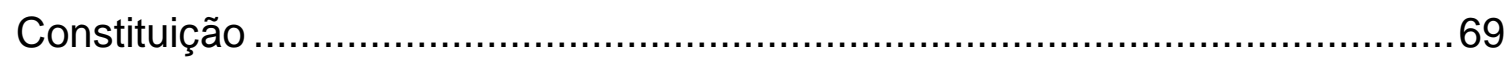

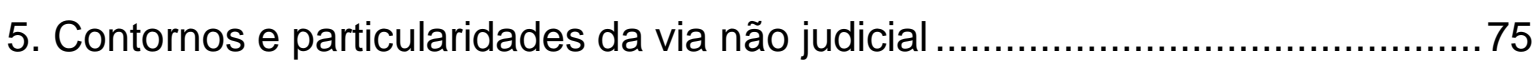

6. A atuação extrajudicial de atores estatais .................................................97

6.1. A indisponibilidade do interesse público e a negociabilidade de direitos sociais

6.2. A pluralidade de agentes no direito positivo brasileiro e o diálogo

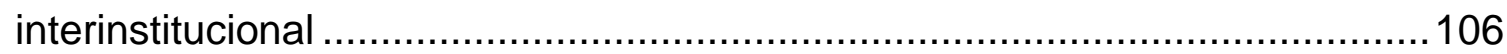

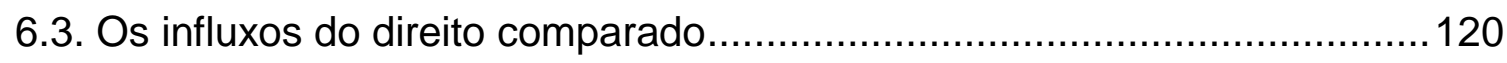

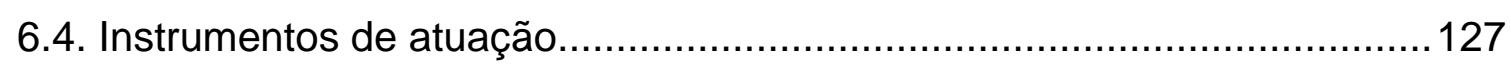

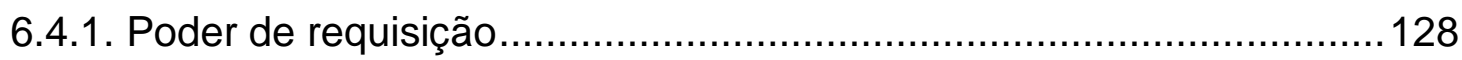

6.4.2. Recomendação e instrumentos análogos .......................................139

6.4.3. Compromisso de ajustamento de conduta .....................................146

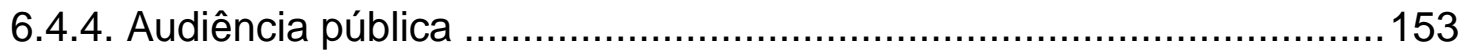

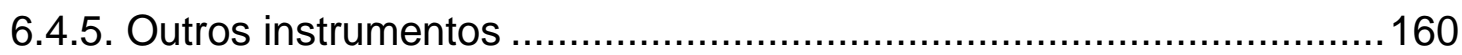

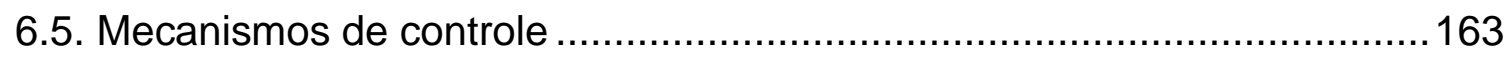

6.6. Casos concretos de atuação estatal ....................................................172

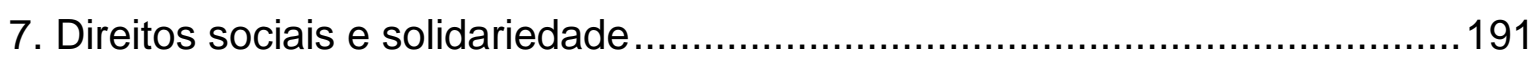

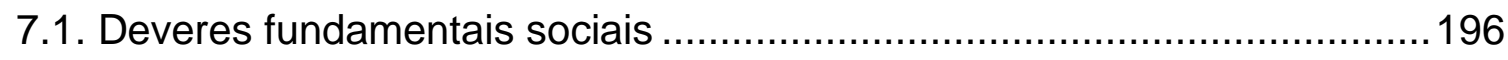

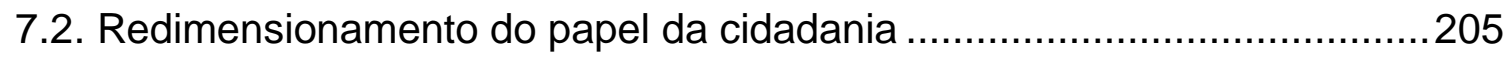

7.3. Impacto potencial da atuação da sociedade civil .....................................212

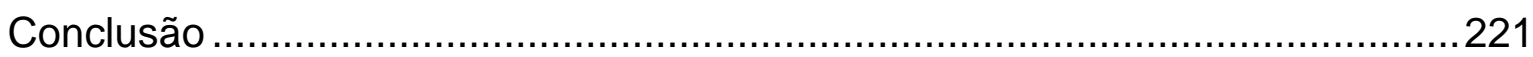

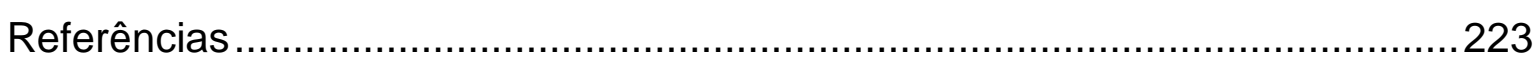





\section{INTRODUÇÃO}

A temática da concretização dos direitos sociais normalmente é associada à discussão relativa à implementação judicial desses direitos, em demandas usualmente apresentadas por indivíduos em face do Estado.

Essa é, contudo, apenas uma faceta do tema.

São plúrimas as possibilidades de efetivação de direitos sociais através de medidas aplicáveis no campo não judicial, e o propósito do presente estudo é justamente explorar essas outras vertentes, demonstrando como direitos sociais podem ser efetivados independentemente da intervenção do Poder Judiciário, seja pela atuação de outros atores estatais, seja pela atuação da própria sociedade civil.

O estudo será permeado pela exposição de casos que ilustrarão os gigantescos benefícios potenciais auferíveis da ocupação progressiva do espaço extrajudicial de efetivação de direitos sociais, por atores públicos e privados.

No que toca a direitos pleiteáveis junto ao poder público, mostrar-seá como não há mais espaço, no mundo atual, para uma Administração Pública resistente à efetivação de direitos pela via consensual e apegada ao comodismo do processo judicial, em que as decisões sobre os rumos da coisa pública são impostas pelo juiz ao gestor, que com isso não assume por elas o correspondente ônus político.

Para além dos questionamentos afetos à (i)legitimidade democrática da intervenção judicial na conformação de políticas públicas, serão demonstrados, na trilha dos problemas do ativismo do Judiciário, como atuações outras podem se revelar mais céleres, efetivas e legítimas.

O caminho percorrido no texto demonstrará que é tempo de a Administração assumir a responsabilidade plena pela gestão da coisa pública, de maneira aberta aos influxos de órgãos outros que não apenas o Judiciário, e especialmente de modo transparente e responsivo às demandas da população.

Não há mais tempo, no frenético mundo atual, para o rito lento e rígido do processo judicial quando se trata de demandas relativas a interesses coletivos e a políticas públicas, e alternativas existem nesse cenário, que não 
apenas aguardar indefinidamente que os responsáveis ajam por sua própria iniciativa.

De outro lado, será discutido o alcance do objetivo constitucional de construção de uma sociedade solidária, deixando-se claro o papel absolutamente essencial da cidadania na efetivação de direitos sociais - seja pela atuação direta de setores da sociedade, seja especialmente pela participação mais ativa no controle e até mesmo na construção de políticas públicas.

Será demonstrado, pois, como a busca por direitos sociais pode se dar pela interlocução não apenas junto à Administração Pública, mas também junto a agentes privados.

Embora o enfoque inicial do texto venha a recair nos limites e possibilidades de atuação de órgãos e entes estatais, será dado ao final algum espaço à discussão relativa à existência de deveres fundamentais sociais - a justificar a busca da responsabilidade de atores privados pelo resguardo ou pela implementação de certos direitos, como decorrência da assunção de determinadas posições jurídicas.

Por certo, não obstante a responsabilidade primária pela implementação de direitos sociais e pela definição de políticas públicas incumba ao Estado, o ordenamento não apenas abre espaço para a atuação da própria sociedade civil em certos nichos, como fomenta atuações privadas voltadas à consecução do interesse público primário e, quanto a certos direitos, impõe deveres reflexos.

A exposição indicará ainda o crescimento do interesse dos cidadãos no acompanhamento e na discussão de seus direitos, e como esse fenômeno tem potencializado o controle popular da coisa pública - inclusive por meio das facilidades inerentes à tecnologia da informação.

Como reflexo da instantaneidade das notícias e da rapidez da publicação de demandas sociais, surge uma expectativa legítima por resultados e mudanças também céleres, de modo que não há mais lugar para uma cidadania passiva e acrítica, à eterna espera de mudanças estatais prometidas em campanhas e raramente implementadas sem alguma cobrança social.

Numa sociedade, como a brasileira, marcada por extrema desigualdade social e por ausência de patamares uniformes mínimos de 
dignidade, o tempo das mudanças deve acompanhar o volume, a complexidade e o ritmo de crescimento dos problemas sociais.

É de ser construída, assim, uma cultura mais difusa de responsabilidade pelos rumos sociais e pelo trato da coisa pública.

Pelo Estado-Administração, não mais a beligerância processual e o protelar infindável de recursos, mas o tratamento sério e eficaz dos anseios populares, sem o recurso ao paternalismo do Estado-Juiz.

Pelos órgãos de controle e pelos atores atuantes como um todo no sistema jurídico estatal, não mais o tratamento protocolar e formal dos pleitos sociais e dos casos sob sua apreciação, nem tampouco o demandismo que simplesmente transfere a outro ente - o Judiciário - a responsabilidade pela solução dos problemas. O que se espera - e o trabalho se presta a contribuir à satisfação desse anseio - é a atuação resolutiva, proativa e séria no tratamento dos direitos sociais.

Pela sociedade, por sua vez, o exercício do protagonismo que the cabe, com a assunção de uma cidadania cada vez mais presente, participativa e solidária, e com a delimitação de uma responsabilidade social pela consecução de deveres de cooperação com a melhoria da coisa pública.

O estudo procurará demonstrar ainda como essas mudanças já vêm tendo curso, e de maneira acelerada.

A consensualidade tem sido cada vez mais fomentada no sistema jurídico pátrio e albergada inclusive e especialmente em pleitos perante a Administração.

Antes circunscritos os termos de ajustamento de conduta (TACs) a atuações esparsas de membros do Ministério Público atuantes na tutela coletiva de direitos, hoje fazem parte da rotina institucional de diversos órgãos públicos, mesmo em matéria de direitos tradicionalmente reputados como indisponíveis.

Órgãos públicos com perfil de atuação originariamente mais restrito, como a Defensoria Pública, vêm também ocupando esse espaço da consensualidade extrajudicial no enfrentamento resolutivo de questões sociais de abrangência coletiva.

Os Tribunais de Contas e, mais limitadamente, os órgãos de controle interno, também têm assumido o papel que lhes é possível exercer nesse campo, contribuindo, pelo controle sobretudo financeiro de políticas públicas, para 
o resguardo da capacidade estatal de arcar com suas obrigações em matéria de direitos sociais.

As advocacias públicas, por seu turno, têm se reestruturado para albergar cada vez mais as soluções consensuais, assumindo maior protagonismo no debate jurídico de políticas públicas.

O estudo transitará por todas essas esferas de atuação extrajudicial - passando ainda pelo papel passível de ser exercido por agências reguladoras no contexto dos direitos sociais -, dando o destaque devido à figura do Ministério Público, instituição vocacionada por excelência para esse mister de atuação extrajudicial na tutela coletiva de direitos sociais.

Serão delimitados os instrumentos jurídicos à disposição de cada um desses atores, com enfrentamento da legitimidade e da resolutividade de suas atuações, sendo trazidos, sempre que possível, casos concretos ilustrativos das respectivas atuações.

Será mostrado como os instrumentos já disponibilizados pelo ordenamento a esses agentes são muitas vezes suficientes, por si sós, para a própria solução dos problemas enfrentados, e não apenas para a coleta de elementos aptos a subsidiar a judicialização das questões (no caso de órgãos também dotados de legitimação processual para litigar em juízo).

Será destacada a mudança de cultura que vem acompanhando esse processo, em que a via judicial é deixada como medida residual a ser porventura adotada apenas em caso de insucesso nas tentativas de solução dialogada.

Da cultura, pois, da sentença para a cultura da pacificação.

Dada a nota de indisponibilidade que caracteriza tanto os direitos sociais quanto a atuação da Administração, serão enfrentados os limites da consensualidade nesse campo.

É de ser superada a ideia de que à Administração cabe resistir, pela nota da indisponibilidade do interesse de que é titular, ao diálogo.

O que se vem notando - como será indicado pela exposição de casos - é a progressiva adoção de uma postura aberta à argumentação jurídica e à construção de soluções criativas que atendam aos reclamos sociais.

Será mostrado ainda como a sociedade tem cada vez mais se conscientizado do peso de seu papel na definição dos rumos sociais, por vezes cobrando diretamente medidas do gestor público, por vezes apoiando atuações 
institucionais de órgãos de Estado vocacionados à tutela coletiva, ou ainda manifestando-se publicamente acerca da maior ou menor aceitabilidade de políticas públicas, ou sobre a maior ou menor premência de medidas estatais neste ou naquele campo, eventualmente assumindo até, ela própria, a responsabilidade solidária por contribuir, tanto quanto possível, para a solução dos problemas sociais.

O trabalho, como dito, trará casos concretos aptos a ilustrar a pluralidade de atuações possíveis no campo extrajudicial, pelos mais diversos atores, públicos e privados, com o fito de demonstrar como, com criatividade, é possível construir soluções rápidas e palpáveis.

Será delineada, em suma, a mudança de mentalidade em curso em matéria de direitos sociais.

O Estado social não consegue acompanhar o crescimento populacional e garantir sozinho, como pretenso segurador universal, o acesso igualitário a todos os direitos constitucionalmente previstos.

A defesa pura e simples da força normativa do texto constitucional é insuficiente para impor todas as medidas necessárias, num cenário de finitude de recursos financeiros.

O momento é, pois, de valorização da democracia cidadã, com a participação mais ativa da sociedade - seja diretamente, seja por intermédio da voz de órgãos estatais inseridos na esfera pública - junto à Administração.

É também momento de despertar para os deveres sociais de contribuir, paralelamente ao Estado, para a construção da sociedade solidária que o texto constitucional objetiva.

Espaço há, de sobra, para a efetivação não judicial de pleitos sociais, e o trabalho cuidará de apresentar um pouco desse despertar da sociedade para uma forma diferente de lutar por seus direitos. 
Assim é que grande parte de iniciativas privadas tem seguimento possível a partir do financiamento por empresas privadas - seja pela consciência, por essas empresas, de sua função social, seja pela possibilidade de explorarem com esse apoio a publicidade positiva daí decorrente.

Ressalte-se, por fim, que não se desconhece a possibilidade de que haja uso deturpado de instituições do terceiro setor por pessoas que, valendo-se de convênios de repasse de verbas públicas, não prestem as contas devidas acerca dos gastos, e cujos dirigentes se valham do manto da solidariedade para conseguir proveitos próprios. ${ }^{402}$

Esses casos eventualmente existentes, contudo, não afastam o mérito de grande parcela de instituições sérias, que não dependem do apoio estatal para funcionar, não obstante o alcance de suas atividades seja evidentemente impactado pelo maior ou menor apoio governamental.

Também não afetam o argumento que aqui se pretende apresentar, no sentido de que não apenas é possível implementar direitos sociais por intermédio de atores jurídicos alheios ao Judiciário, como também é possível fazê-lo sem a própria participação do Estado, a partir do protagonismo de uma cidadania ativa e solidária da própria sociedade.

Em verdade, tanto aqui quanto nos casos já vistos de efetivação não judicial desses direitos por intermédio da atuação de atores estatais, o alcance e a efetividade dos trabalhos é diretamente influenciado pelo grau de participação popular.

No fim das contas, é a cidadania ativa e a participação tão direta quanto possível da sociedade que trazem eficácia à busca pela implementação de direitos sociais.

402 Em hipóteses tais há necessidade de devida responsabilização, pelos mecanismos de controle que $\mathrm{o}$ ordenamento disponibiliza para a repressão de condutas irregulares como as narradas. 


\section{CONCLUSÃO}

Falar em concretização de direitos sociais outrora significava aguardar a boa vontade do Executivo em fazer cumprir promessas de campanha, ou mesmo aguardar mudanças legislativas lentas e influenciadas por variados grupos de pressão.

À sociedade civil não organizada restavam poucos mecanismos de atuação, que não manifestar seus interesses por ocasião das próximas eleições, num ciclo de renovadas esperanças e parcas realizações.

Com a evolução da compreensão majoritária acerca da eficácia da norma constitucional garantidora de direitos - mesmo daqueles de cunho social -, o Judiciário passou a ser mais receptivo à tese da possibilidade de que decisões judiciais pudessem intervir na execução e até mesmo na formulação de políticas públicas, como forma de suprir as posturas omissivas de Executivo e Legislativo e fazer observar a juridicidade do texto constitucional.

A disseminação dessa postura judicial acabou por gerar resistências até mesmo na doutrina constitucional, que passa a repensar a legitimidade dessa atuação e a propugnar pelo estabelecimento de limites.

$\mathrm{Na}$ esteira dessas críticas e como reflexo sobretudo do assoberbamento do Judiciário para dar vazão a todas as demandas que passaram a lhe ser trazidas, o espaço da efetivação de direitos sociais passou a ser progressivamente ocupado por outros atores, interessados não no manejo de sua legitimidade processual ativa, mas sim de outros instrumentos hábeis a viabilizar a solução de pleitos sociais sem a necessidade de levar sua apreciação à via judicial.

Esse cenário foi favorecido e impactado pela paulatina mudança cultural que vem havendo em prol da valorização de soluções consensuais, bem como pela facilitação do controle social e da participação popular na esfera pública a partir sobretudo do avanço das tecnologias digitais. 
Pretendeu-se neste estudo chamar a atenção para essa mudança em curso, indicando como a própria sociedade vem se dando conta de que em muitos casos é mais efetiva a busca da atuação de órgãos estatais outros que não o Judiciário, ou mesmo a mobilização de setores dela própria, sociedade.

O debate acerca da concretização de direitos constitucionais prestacionais não deve deixar de lado o impacto potencial de atuações possíveis no campo não judicial, razão pela qual a pesquisa procurou não apenas discutir os instrumentos jurídicos que viabilizam a intervenção exitosa de atores variados (públicos e privados) nesse campo, mas também expor diversos casos ilustrativos de como mudanças sociais palpáveis podem ser obtidas extrajudicialmente.

O fato é que a categoria dos direitos fundamentais sociais se revela hoje imprescindível para a consecução do modelo de sociedade desenhado no texto constitucional, o que impõe o aprofundamento dos estudos sobre os caminhos possíveis para sua efetivação. 


\section{REFERÊNCIAS}

ACKERMAN, Bruce. The new separation of powers. Harvard Law Review, v. 113, n. 3: 633-729, jan. 2000. Disponível em: http://www.jstor.org/stable/1342286. Acesso em 04.06.2017.

ALEXANDER, Larry; SCHAUER, Frederick. On Extrajudicial Constitutional Interpretation. Harvard Law Review, v. 110, n. 7: 1359-1387, may 1997. Disponível em: http://www.jstor.org/stable/1342175. Acesso em 04.04.2017.

ALEXY, Robert. Teoria da argumentação jurídica: a teoria do discurso racional como teoria da justificação jurídica. Trad. Zilda Hutchinson Schild Silva. $2^{2}$ ed. São Paulo: Landy Editora, 2005.

. Teoria dos direitos fundamentais. Trad. Virgílio Afonso da Silva. $2^{\underline{a}}$ ed. São Paulo: Malheiros, 2015.

ALMEIDA, Gregório Assagra de. O Ministério Público no neoconstitucionalismo: perfil constitucional e alguns fatores de ampliação de sua legitimação social. In: FARIAS, Cristiano Chaves de; ALVES, Leonardo Barreto Moreira; ROSENVALD, Nelson. Temas atuais do Ministério Público. 6ª ed. Salvador: Juspodivm, 2016, p. 55-124.

AMARAL JUNIOR, José Levi Mello do (coord.). Estado de Direito e Ativismo Judicial. São Paulo: Quartier Latin, 2010.

ARANGO, Rodolfo. El concepto de derechos sociales fundamentales. Colombia: Legis, 2005.

ARMAS, Pedro Carballo. El Defensor del Pueblo: el ombudsman en España y en el derecho comparado. Madrid: Tecnos, 2003.

ASENSI, Felipe Dutra. Indo além da judicialização: o Ministério Público e a saúde no Brasil. Disponível em: http://bibliotecadigital.fgv.br/dspace/handle/10438/10313. Acesso em 10.06.2017. 
ASENSI, Felipe et. al. Ministério Público e estratégias de efetivação do direito à saúde no Brasil. Disponível em http://www.portaldeperiodicos.unisul.br /index.php/U_Fato_Direito/article/view/2823. Acesso em 25.09.2017.

ASENSI, Felipe Dutra; PINHEIRO, Roseni (coord.). Judicialização da saúde no Brasil: dados e experiência. Brasília: Conselho Nacional de Justiça, 2015. Disponível em: http://www.cnj.jus.br/files/conteudo/destaques/arquivo/2015/06 /6781486daef02bc6ec8c1e491a565006.pdf. Acesso em 07.11.2017.

BARCELLOS, Ana Paula de. Um debate para o neoconstitucionalismo. Papéis do Direito Constitucional no fomento do controle social democrático: algumas propostas sobre o tema da informação. In: FRANCISCO, José Carlos (coord.). Neoconstitucionalismo e atividade jurisdicional: do passivismo ao ativismo judicial. Belo Horizonte: Del Rey, 2012, p. 155-192.

BARREIROS, Lorena Miranda Santos. Convenções processuais e poder público. Salvador: Juspodivm, 2017.

BARROSO, Luís Roberto. Da falta de efetividade à judicialização excessiva: direito à saúde, fornecimento gratuito de medicamentos e parâmetros para a atuação judicial. In: SOUZA NETO, Cláudio Pereira de; SARMENTO, Daniel (coord.). Direitos sociais: fundamentos, judicialização e direitos sociais em espécie. Rio de Janeiro: Lumen Juris, 2008, p. 875-903.

- Neoconstitucionalismo e constitucionalização do direito: o triunfo tardio do direito constitucional no Brasil. Disponível em: http://www.luisrobertobarroso.com.br/wpcontent/themes/LRB/pdf/neoconstitucionalismo_e_constitucionalizacao_do_direito _pt.pdf. Acesso em 04.07.2017.

BASTOS, Aurélio Wander Chaves. Conflitos sociais e limites do Poder Judiciário: subsídio metodológico para a compreensão do procedimento judiciário. Rio de Janeiro: Eldorado Tijuca, 1975. 
BATEUP, Christine. The Dialogic Promise Assessing The Normative Potential of Theories of Constitutional Dialogue. Brooklyn Law Review, v. 71: 1109-1180, 2006. Disponível em LexisNexis Academic. Acesso em 04.06.2017.

BATISTA, Flávio Roberto. Crítica da tecnologia dos direitos sociais: uma contribuição materialista histórico-dialética. Tese de Doutorado. Faculdade de Direito da Universidade de São Paulo, 2012.

BINENBOJM, Gustavo. Da supremacia do interesse público ao dever de proporcionalidade: um novo paradigma para o direito administrativo. In: BINENBOJM, Gustavo. Temas de direito administrativo e constitucional. Rio de Janeiro: Renovar, 2008, p. 61-94.

BONAVIDES, Paulo. Curso de Direito Constitucional. 28 a ed. São Paulo: Malheiros, 2013.

BURGER, Adriana Fagundes et. al (org.). Defensoria Pública: o reconhecimento constitucional de uma metagarantia. Brasília : ANADEP, 2015. Disponível em https://www.anadep.org.br/wtksite/AF_E-book_Metagarantia.pdf. Acesso em 26.09.2017.

CABRAL, Antonio do Passo. Convenções processuais. Salvador: Juspodivm, 2016.

A resolução no 118 do Conselho Nacional do Ministério Público e as convenções processuais. In: CABRAL, Antonio do Passo; NOGUEIRA, Pedro Henrique (coord.). Negócios processuais. $3^{\underline{a}}$ ed. Salvador: Juspodivm, 2017, p. 709-725.

CALABRICH, Bruno (org.). Modelos de Ministérios Públicos e Defensorias del Pueblo, v. 3. Brasília: ESMPU, 2014.

CANOTILHO, J. J. et. al. (coord.). Comentários à Constituição do Brasil. São Paulo: Saraiva, 2014.

CAPPELLETTI, Mauro. Vindicating the Public Interest through the Courts: A Comparativist's Contribution. Buffalo Law Review, n. 25: 643-690, 1976. 
Disponível

em

http://heinonline.org/HOL/Page?handle=hein.journals/buflr25\&start_page=643\&col lection=journals\&id=655. Acesso em 25.10.2017.

Juízes legisladores? Trad. Carlos Alberto Alvaro de Oliveira. Porto Alegre: Sergio Antonio Fabris Editor, 1993.

CAPPELLETTI, Mauro; GARTH, Bryant. Acesso à Justiça. Trad. Ellen Gracie Northfleet. Porto Alegre: Sergio Antonio Fabris Editor, 1988.

CARAJELESCOV, Yuri. Mídia, direito, desenvolvimento e democracia no Brasil. Tese de Doutorado. Faculdade de Direito da Universidade de São Paulo, 2016.

CÁRCOVA, Carlos Maria. Direito, política e magistratura. Trad. Rogério Viola Coelho e Marcelo Ludwig Dornelles Coelho. São Paulo: LTr, 1996.

CARNAES, Mariana. Compromisso de ajustamento de conduta e eficiência administrativa. Rio de Janeiro: Lumen Juris, 2016.

CARVALHO, José Murilo de. Cidadania no Brasil: o longo caminho. 19å ed. Rio de Janeiro: Civilização Brasileira, 2015.

CASAGRANDE, Cássio. Ministério Público e a judicialização da política: estudos de casos. Porto Alegre: Sergio Antonio Fabris, 2008.

CASTILHO, Ela Wiecko V. de. A Procuradoria dos Direitos do Cidadão. Disponível em http://pfdc.pgr.mpf.mp.br/atuacao-e-conteudos-de-apoio/publicacoes/direitoshumanos/a-procuradoria-dos-direitos-do-cidadao-elawiecko-2011. Acesso em 19.11.2017.

CAVALCANTI, Thais Novaes. Direitos fundamentais e o princípio da subsidiariedade: por uma teoria sobre o desenvolvimento humano. Osasco: Edifieo, 2015.

CITTADINO, Gisele. Judicialização da política, constitucionalismo democrático e separação de Poderes. In: VIANNA, Luiz Werneck (org.). A democracia e os três 
Poderes no Brasil. Belo Horizonte: Editora UFMG; Rio de Janeiro: IUPERJ, FAPERJ, 2003, p. 337-491.

COELHO, Inocêncio Mártires. As ideias de Peter Haberle e a abertura da interpretação constitucional no Direito Brasileiro. Revista de Informação legislativa, v. 35, n. 137: 157-164, jan./mar. 1998.

COMPARATO, Fábio Konder. A afirmação histórica dos direitos humanos. $7^{\mathfrak{a}}$ ed. São Paulo: Saraiva, 2010.

- Direitos e deveres fundamentais em matéria de propriedade. Revista CEJ, v.1. n.3: 92-99, dez. 1997. Disponível em http://www.cjf.jus.br/ojs2/index.php/revcej/article/view/123/166. Acesso em 07.10.2017.

CUNHA JUNIOR, Dirley da. A efetividade dos direitos fundamentais sociais e a reserva do possível. In: NOVELINO, Marcelo (org.). Leituras complementares de Direito Constitucional: direitos humanos e direitos fundamentais. $3^{\text {a }}$ ed. Salvador: Juspodivm, 2008, p. 349-395.

DEMARCHI, JULIANA. Mediação: proposta de implementação no processo civil brasileiro. Tese de Doutorado. Faculdade de Direito da USP, 2007.

DIDIER JR., Fredie. Curso de Direito Processual Civil, v. 1. 10 a ed. Salvador: Juspodivm, 2008.

DIDIER JR., Fredie; ZANETI JR., Hermes. Justiça multiportas e tutela constitucional adequada: autocomposição em direitos coletivos. In: ZANETI JR., Hermes; CABRAL, Trícia Navarro Xavier (coord.). Justiça multiportas: mediação, conciliação, arbitragem e outros meios de solução adequada de conflitos. Salvador: Juspodivm, 2016, p. 35-66.

DIMOULIS, Dimitri. Neoconstitucionalismo e moralismo jurídico. Disponível em: http://www.academia.edu/1615334/Neoconstitucionalismo_e_moralismo_jur\%C3 \%ADdico. Acesso em 11.05.2018. 
DWORKIN, Ronald. Equality, Democracy, and Constitution: We the People in Court. Alberta Law Review, v. 28, n. 2: 324-346, 1990. Disponível em http://heinonline.org/HOL/Page?handle=hein.journals/alblr28\&id=340. Acesso em 29.10.2017.

. Uma questão de princípio. Trad. Luis Carlos Borges. $2^{\underline{a}}$ ed. São Paulo: Martins Fontes, 2005.

. O império do direito. Trad. Jefferson Luiz Camargo. $2^{\underline{a}}$ ed. São Paulo: Martins Fontes, 2007.

Levando os direitos a sério. Trad. Nelson Boeira. $3^{\mathrm{a}}$ ed. São Paulo: Martins Fontes, 2010.

FERRAZ, Anna Candida da Cunha. Processos informais de mudança da Constituição: mutações constitucionais e mutações inconstitucionais. São Paulo: Max Limonad, 1986.

Aspectos da positivação dos direitos fundamentais na Constituição de 1988. In: BITTAR, Eduardo C. B.; FERRAZ, Anna Candida da Cunha (org.). Direitos humanos fundamentais: positivação e concretização. Osasco: Edifieo, 2006, p. 115-181.

A projeção da democracia participativa na jurisdição constitucional no Brasil: as audiências públicas e sua adoção no modelo concentrado de constitucionalidade. In: HORBACH, Carlos Bastide; ALMEIDA, Fernando Dias Menezes; AMARAL JÚNIOR, José Levi Mello do; LEAL, Roger Stiefelmann (coord.). Direito constitucional, Estado de Direito e democracia: homenagem ao prof. Manoel Gonçalves Ferreira Filho. São Paulo: Quartier Latin, 2011, p. 75-120.

FERRAZ, Anna Candida da Cunha; ALMEIDA, Fernanda Dias Menezes de. Interpretação constitucional: o controle judicial da atividade política. In: MOREIRA, Eduardo Ribeiro et. al. (org.). Hermenêutica constitucional: homenagem aos 22 anos do grupo de estudos Maria Garcia. Florianópolis: Conceito Editorial, 2010, p. 63-75. 
FERRAZ JUNIOR, Tercio Sampaio. Notas sobre contribuições sociais e solidariedade no contexto do Estado Democrático de Direito. In: GRECO, Marco Aurélio; GODOI, Marciano Seabra de. Solidariedade social e tributação. São Paulo: Dialética, 2005, p. 208-221.

Interpretação das normas constitucionais. In: ROCHA, Maria Elizabeth Guimarães Teixeira; PETERSEN, Zilah M. C. F. (coord.). Coletânea de estudos jurídicos. Brasília: Superior Tribunal Militar, 2008, p. 447-454.

FERREIRA FILHO, Manoel Gonçalves. Poder Judiciário na Constituição de 1988: judicialização da política e politização da Justiça. Revista de Direito Administrativo, n. 198: 1-17, out./dez. 1994.

Direitos Humanos Fundamentais. 12 ed. São Paulo: Saraiva, 2010.

FLETCHER, Agnes; O’BRIEN, Nick. Disability Rights Commission: From Civil Rights to Social Rights. Journal of Law and Society, v. 35, n. 4: 520-550, dec. 2008. Disponível em http://www.jstor.org/stable/40206864. Acesso em 25.10.2017.

FONSECA, Igor Ferraz da et. al. Audiências públicas do Poder Executivo Federal: fatores de efetividade. Texto para Discussão, n. 1873. Brasília: Instituto de Pesquisa Econômica Aplicada, set. 2013. Disponível em http://www.ipea.gov.br/portal/images/stories/PDFs/TDs/td_1873.pdf. Acesso em 05.03.2018.

FRISCHEISEN, Luiza Cristina Fonseca. Políticas públicas: a responsabilidade do administrador e o Ministério Público. São Paulo: Max Limonad, 2000.

GABBAY, Daniela Monteiro; CUNHA, Luciana Gross (coord.). O Desenho de Sistemas de Resolução Alternativa de Disputas para Conflitos de Interesse Público. Série Pensando o Direito, n. 38. São Paulo: Fundação Getúlio Vargas, 2011.

GABBAY, Daniela Monteiro; TAKAHASHI, Bruno. Desenho de sistemas e mecanismos consensuais de solução de conflitos na Justiça Federal: uma 
introdução. In: GABBAY, Daniela Monteiro; TAKAHASHI, Bruno (coord.). Justiça Federal: inovações nos mecanismos consensuais de solução de conflitos. Brasília: Gazeta Jurídica, 2014, p. 3-33.

GALDINO, Flávio. Introdução à teoria dos custos dos direitos: direitos não nascem em árvores. Rio de Janeiro: Lumen Juris, 2005.

GARGARELLA, Roberto. ¿Democracia deliberativa y judicialización de los derechos sociales? Perfiles Latinoamericanos, n. 28: 9-32, jul./dic. 2006.

GODOI, Marciano Seabra. Tributo e solidariedade social. In: GRECO, Marco Aurélio; GODOI, Marciano Seabra de. Solidariedade social e tributação. São Paulo: Dialética, 2005, p. 141-167.

GOLDBERG, Stephen B. et. al. Dispute resolution: negotiation, mediation, and other processes. 5th ed. New York: Aspen Publishers, 2007.

GOMES, Juliana Cesario Alvim. Por um constitucionalismo difuso: cidadãos, movimentos sociais e o significado da Constituição. Salvador: Juspodivm, 2016.

GOMEZ, Mario. Social Economic Rights and Human Rights Commissions. Human Rights Quarterly, v. 17, n. 1: 155-169, feb. 1995. Disponível em: http://www.jstor.org/stable/762351. Acesso em 04.04.2017.

GONÇALVES, Marcelo Barbi. Jurisdição condicionada e acesso à justiça: considerações sobre a escalada de tutelas contra a Fazenda Pública. Revista de Processo, v. 41, n. 252: 319-338, fev. 2016.

GONÇALVES FILHO, Edilson Santana. Defensoria tem perfil para ser ombudsman na solução extrajudicial de conflitos. Revista Consultor Jurídico, mai. 2017. Disponível em: https://www.conjur.com.br/2017-mai-09/tribuna-defensoriadefensoria-ombudsman-solucao-extrajudicial-conflitos. Acesso em 19.11.2017.

GOULART, Marcelo Pedroso. Missão institucional do Ministério Público. Revista Jurídica da Escola Superior do Ministério Público de São Paulo, v. 1, n. 1: 9-32, jan./jun. 2001. 
GRECO, Marco Aurélio. Solidariedade social e tributação. In: GRECO, Marco Aurélio; GODOI, Marciano Seabra de. Solidariedade social e tributação. São Paulo: Dialética, 2005, p. 168-189.

GRINOVER, Ada Pellegrini. O controle jurisdicional de políticas públicas. In: GRINOVER, Ada Pellegrini; WATANABE, Kazuo (coord.). O controle jurisdicional de políticas públicas. Rio de Janeiro: Forense, 2011, p. 125-150.

GRINOVER, Ada Pellegrini; LUCON, P. H. S.; WATANABE, Kazuo. PL sobre controle jurisdicional de políticas públicas é constitucional. Disponível em: https://www.conjur.com.br/2015-fev-23/pl-controle-jurisdicional-politica-publicaconstitucional. Acesso em 07.11.2017.

Ensaio sobre a processualidade: fundamentos para uma nova teoria geral do processo. Brasília: Gazeta Jurídica, 2016.

GUERRERO, Luis Fernando. Efetividade das estipulações voltadas à instituição dos meios multiportas de solução de litígios. Tese de Doutorado. Faculdade de Direito da Universidade de São Paulo, 2012.

HÄBERLE, Peter. Hermenêutica constitucional: a sociedade aberta dos intérpretes da Constituição - contribuição para a interpretação pluralista e "procedimental" da Constituição. Trad. Gilmar Ferreira Mendes. Porto Alegre: Sergio Antonio Fabris Editor, 2002.

- Pluralismo y Constitución: estudios de Teoría Constitucional de la sociedad aberta. Trad. Emilio Mikunda-Franco. Madrid: Tecnos, 2002.

. Le libertà fondamentali nello stato costituzionale. Trad. Alessandro Fusillo e Romolo Rossi. Roma: Carocci Editore, 1993.

HABERMAS, Jürgen. Mudança estrutural da esfera pública: investigações quanto a uma categoria da sociedade burguesa. Trad. Flávio R. Kothe. Rio de Janeiro: Tempo Brasileiro, 1984.

. Direito e democracia: entre facticidade e validade. Trad. Flávio Beno Siebeneichler. $2^{\underline{a}}$ ed. Rio de Janeiro: Tempo Brasileiro, 2011. 
HESSE, Konrad. A força normativa da Constituição. Trad. Gilmar Ferreira Mendes. Porto Alegre: Sergio Antonio Fabris Editor, 1991.

HOLMES, Stephen; SUNSTEIN, Cass R. The cost of rights: why liberty depends on taxes. New York: W.W.Norton \& Company, 2000.

KELLES, Márcio Ferreira. Controle da Administração Pública Democrática: Tribunal de Contas no controle da LRF. Belo Horizonte: Fórum, 2007.

KING, Jeff. Judging social rights. Cambridge: Cambridge University Press, 2012.

LEIVAS, Paulo Gilberto Cogo. Teoria dos direitos fundamentais sociais. Porto Alegre: Livraria do Advogado, 2006.

LIMA, George Marmelstein. Críticas à teoria das gerações (ou mesmo dimensões) dos direitos fundamentais. Revista Jus Navigandi, v.8, n. 173, 26 dez. 2003. Disponível em https:/jus.com.br/artigos/4666. Acesso em: 31 mar. 2018.

LOBO, Júlio Cesar Matias. A atuação do Defensor Público à luz da Administração Gerencial Pública do século XXI. In: ROCHA, Amélia et. al. (org.). Defensoria Pública, assessoria jurídica popular e movimentos sociais e populares: novos caminhos traçados na concretização do direito de acesso à justiça. Fortaleza: Dedo de Moças Editora, 2013, p. 227-270. Disponível em https://www.anadep.org.br/wtksite/LIVRO.pdf. Acesso em 26.09.2017.

LOPES, José Reinaldo de Lima. Direito subjetivo e direitos sociais: o dilema do Judiciário no Estado Social de Direito. In: FARIA, José Eduardo (org.). Direitos humanos, direitos sociais e justiça. São Paulo: Malheiros, 1998, p. 113-143.

LÓPEZ, Manuel García Álvarez-Rubén García. El papel de los defensores del pueblo como impulsores de la modificación del ordenamiento jurídico: una garantía adicional de desarrollo del Estado social. Teoría y Realidad Constitucional, n. 26: 127-165, 2010.

LUNA, Ana Cláudia Vergamini. Direitos sociais: controle jurisdicional de políticas públicas, limites e possibilidades. Dissertação de mestrado. Faculdade de Direito da Universidade de São Paulo, 2012. 
MAIORANO, Jorge Luis. El ombudsman en America Latina. Revista de Informação Legislativa, v. 23, n. 92: 241-256, out./dez. 1986. Disponível em http://www2.senado.leg.br/bdsf/bitstream/handle/id/181738/000427078.pdf?seque nce $=3$. Acesso em 21.10.2017.

MANCUSO, Rodolfo de Camargo. Acesso à justiça: condicionantes legítimas e ilegítimas. São Paulo: Revista dos Tribunais, 2012.

MAZZILLI, Hugo Nigro. O acesso à Justiça e o Ministério Público. $5^{\text {a }}$ ed. São Paulo: Saraiva, 2007.

MELLO, Cláudio Ari. Democracia Constitucional e Direitos Fundamentais. Porto Alegre: Livraria do Advogado Editora, 2004.

MENDES, Conrado Hübner. Direitos fundamentais, separação de poderes e deliberação. São Paulo: Saraiva, 2011.

MERÇON-VARGAS, Sarah. Meios alternativos na resolução de conflitos de interesses transindividuais. Dissertação de mestrado. Faculdade de Direito da Universidade de São Paulo, 2012.

MERRY, Sally Engle. Getting justice and getting even: legal consciousness among working-class americans. Chicago: The University of Chicago Press, 1990.

MIRANDA, Marcos Paulo de Souza. A recomendação ministerial como instrumento extrajudicial de solução de conflitos ambientais. In: FARIAS, Cristiano Chaves de; ALVES, Leonardo Barreto Moreira; ROSENVALD, Nelson. Temas atuais do Ministério Público. 6ª ed. Salvador: Juspodivm, 2016, p. 787-831.

MOTTA, Paulo Roberto Ferreira. Agências reguladoras. Barueri: Manole, 2003.

NABAIS, José Casalta. Solidariedade social, cidadania e direito fiscal. In: GRECO, Marco Aurélio; GODOI, Marciano Seabra de. Solidariedade social e tributação. São Paulo: Dialética, 2005, p. 110-140.

A face oculta dos direitos fundamentais: os deveres e os custos dos direitos. Revista de Direito Público da Economia. Belo Horizonte, v. 5, n. 20: 153181, out./dez. 2007. 
NEVES, Marcelo. A constitucionalização simbólica. São Paulo: Martins Fontes, 2007.

A força simbólica dos direitos humanos. In: SOUZA NETO, Cláudio Pereira de; SARMENTO, Daniel (coord.). Direitos sociais: fundamentos, judicialização e direitos sociais em espécie. Rio de Janeiro: Lumen Juris, 2008, p. 417-450.

A Constituição e a esfera pública: entre diferenciação sistêmica, inclusão e reconhecimento. In: BENEVIDES, Maria Victoria de Mesquita et. al. (org.). Direitos humanos, democracia e república: homenagem a Fábio Konder Comparato. São Paulo: Quartier Latin, 2009, p. 653-688.

OLIVEIRA, Gustavo Justino de; SCHWANKA, Cristiane. A Administração Consensual como a nova face da Administração Pública no séc. XXI: fundamentos dogmáticos, formas de expressão e instrumentos de ação. Revista da Faculdade de Direito da Universidade de São Paulo, v. 104: 303-322, jan./dez. 2009.

PACCAGNELLA, Luíz Henrique. Controle da Administração pelo Ministério Público: meio de aprofundamento da democracia. In: VIGLIAR, José Marcelo Menezes; MACEDO JÚNIOR, Ronaldo Porto (coord.). Ministério Público II: democracia. São Paulo: Atlas, 1999, p. 177-192.

PAIVA, Tomás Filipe Schoeller Borges Ribeiro. A aplicabilidade dos direitos sociais prestacionais nas relações privadas: uma análise sob a ótica da teoria dos deveres de proteção. Tese de Doutorado. Faculdade de Direito da Universidade de São Paulo, 2014.

PALMA, Juliana Bonacorsi de. A consensualidade na Administração Pública e seu controle judicial. In: GABBAY, Daniela Monteiro; TAKAHASHI, Bruno (coord.). Justiça Federal: inovações nos mecanismos consensuais de solução de conflitos. Brasília: Gazeta Jurídica, 2014, p. 143-187.

PEREZ, Marcos Augusto. A participação da sociedade na formulação, decisão e execução das políticas públicas. In: BUCCI, Maria Paula Dallari (org.). Políticas 
públicas: reflexões sobre o conceito jurídico. São Paulo: Saraiva, 2006, p. 163176.

POGREBINSCHI, Thamy. Judicialização ou representação? Política, direito e democracia no Brasil. Rio de Janeiro: Elsevier, 2011.

PROENÇA, Luis Roberto. Inquérito civil: atuação investigativa do Ministério Público a serviço da ampliação do acesso à Justiça. São Paulo: Revista dos Tribunais, 2001.

QUEIROZ, Cristina. Direitos fundamentais sociais: questões interpretativas e limites de justiciabilidade. In: SILVA, Virgílio Afonso da. Interpretação constitucional. São Paulo: Malheiros, 2010, p. 165-216.

RAMOS, André de Carvalho. Defensoría Del Pueblo na Argentina e o Ministério Público brasileiro: a da efetivação dos direitos humanos. In: CALABRICH, Bruno (org.). Modelos de Ministérios Públicos e Defensorías Del Pueblo, v.3. Brasília: ESMPU, 2014, p. 15 39.

RAMOS, Elival da Silva. Controle jurisdicional de políticas públicas: a efetivação dos direitos sociais à luz da Constituição brasileira de 1988. Revista da Faculdade de Direito da Universidade de São Paulo, v. 102: 327-356, jan./dez. 2007.

- Eficácia de normas constitucionais, implementação de direitos fundamentais e ativismo judiciário. In: FRANCISCO, José Carlos (coord.). Neoconstitucionalismo e atividade jurisdicional: do passivismo ao ativismo judicial. Belo Horizonte: Del Rey, 2012, p. 243-260.

. O direito à saúde em face da discricionariedade administrativa. In: MARQUES NETO, Floriano de Azevedo et. al. (org.). Direito e Administração Pública: estudos em homenagem a Maria Sylvia Zanella Di Pietro. São Paulo: Atlas, 2013.

Ativismo judicial: parâmetros dogmáticos. $2^{\underline{a}}$ ed. São Paulo: Saraiva, 2015. 
REYES S., Pedro Miguel; BRICENO VIVAS, Gustavo. Insuficiencia de los controles tradicionales sobre la administracion. Revista de la Facultad de Derecho de la Universidad Andres Bello. Caracas, n.39-40: 199-222, ene./dec. 1988.

RIBEIRO, Diógenes V. Hassan. Judicialização e desjudicialização: entre a deficiência do legislativo e a insuficiência do Judiciário. Revista de Informação Legislativa, v. 50, n. 199: 25-33, jul./set. 2013.

$\mathrm{ROACH}$, Kent. A Dialogue about Principle and a Principled Dialogue: Justice lacobucci's Substantive Approach to Dialogue. The University of Toronto Law Journal, v. 57, n. 2: 449-477, 2007. Disponível em: http://www.jstor.org/stable/4491729. Acesso em 04.06.2017.

RODRIGUES, Geisa de Assis. Ação civil pública e termo de ajustamento de conduta: teoria e prática. $2^{\underline{a}}$ ed. Rio de Janeiro: Forense, 2006.

Anotações sobre a negociação de medidas compensatórias em termo de ajustamento de conduta. In: GABBAY, Daniela Monteiro; TAKAHASHI, Bruno (coord.). Justiça Federal: inovações nos mecanismos consensuais de solução de conflitos. Brasília: Gazeta Jurídica, 2014, p. 621-634.

RODRIGUES, Ricardo Schneider. O controle de políticas públicas pelos Tribunais de Contas. In: SILVA, Jéssica A. C. da; ERHARDT JÚNIOR, Marcos (coord.). Hermenêutica jurídica \& efetivação dos direitos sociais: homenagem a Andreas Krell. Curitiba: Juruá, 2014, p. 183-201.

ROSANVALLON, Pierre. Democratic legitimacy: impartiality, reflexivity, proximity. Transl. Arthur Goldhammer. Princeton: Princeton University Press, 2011.

ROSENBERG, GERALD N. The hollow hope: can courts bring about social change? $2^{a}$ ed. Chicago: The University of Chicago Press, 2008.

ROSENVALD, Nelson. O Ministério Público e a vinculação dos particulares aos direitos fundamentais sociais. In: FARIAS, Cristiano Chaves de; ALVES, Leonardo Barreto Moreira; ROSENVALD, Nelson. Temas atuais do Ministério Público. 6ª ed. Salvador: Juspodivm, 2016, p. 125-159. 
ROSSO, Paulo Sergio. Solidariedade e direitos fundamentais na Constituição brasileira de 1988. Revista Eletrônica do CEJUR, v. 1, n. 2: 201-222, ago./dez. 2007.

SALLES, Carlos Alberto de. Mecanismos alternativos de solução de controvérsias e acesso à Justiça: a inafastabilidade da tutela jurisdicional recolocada. In: FUX, Luiz et. al. (coord.). Processo e Constituição: estudos em homenagem ao professor José Carlos Barbosa Moreira. São Paulo: Revista dos Tribunais, 2006, p. $779-792$.

A indisponibilidade e a solução consensual de controvérsias. In: GABBAY, Daniela Monteiro; TAKAHASHI, Bruno (coord.). Justiça Federal: inovações nos mecanismos consensuais de solução de conflitos. Brasília: Gazeta Jurídica, 2014, p. 209-227.

SAMPAIO, Jose Adércio Leite. A Constituição reinventada pela jurisdição constitucional. Belo Horizonte: Del Rey, 2002.

SANSON, Alexandre. Dos grupos de pressão na democracia representativa: os limites jurídicos. Tese de Doutorado. Faculdade de Direito da Universidade de São Paulo, 2013.

SARLET, Ingo Wolfgang. Segurança social, dignidade da pessoa humana e proibição do retrocesso: revisitando o problema da proteção dos direitos fundamentais sociais. In: CANOTILHO, J.J. Gomes; CORREIA, Marcus Orione Gonçalves; CORREIA, Érica Paula Barcha (coord.). Direitos fundamentais sociais. São Paulo: Saraiva, 2010.

SARLET, Ingo Wolfgang; MARINONI, Luiz Guilherme; MITIDIERO, Daniel. Curso de Direito Constitucional. São Paulo: Revista dos Tribunais, 2012.

SARMENTO, Daniel. Direitos fundamentais e relações privadas. $2^{\underline{a}}$ ed. Rio de Janeiro: Lumen Juris, 2006.

A vinculação dos particulares aos direitos fundamentais no direito comparado e no Brasil. In: BARROSO, Luís Roberto (org.). A nova interpretação 
constitucional: ponderação, direitos fundamentais e relações privadas. $3^{\underline{a}}$ ed. Rio de Janeiro: Renovar, 2008, p. 193-284.

Dimensões Constitucionais da Defensoria Pública da União. Disponível em http://www.anadef.org.br/images/Parecer_ANADEF_CERTO.pdf. Acesso em 19.11.2017.

SCHWARZ, Carl E. Non-judicial remedies for administrative abuse: the mexican experience. Administrative Law Review, v. 29, n. 1: 115-136, 1977. Disponível em: http://www.jstor.org/stable/40709004. Acesso em 04.04.2017.

SILVA, Cátia Aida. Justiça em jogo. São Paulo: Edusp, 2001.

SILVA, José Afonso da. Aplicabilidade das normas constitucionais. $8^{\mathrm{a}}$ ed. São Paulo: Malheiros, 2015.

SILVA, Péricles Batista. A Defensoria Pública na passagem do século XX ao XXI: da atuação judicial individual para a atuação coletiva, interdisciplinar e extrajudicial. In: Livro de teses e práticas exitosas: XI Congresso Nacional de Defensores Públicos, Defensoria Pública e seus novos desafios, p. 98-104. Disponível em https://www.anadep.org.br/wtksite/livro_teses_e_praticas_exitosas2.pdf. Acesso em 26.09.2017.

SILVA, Sandoval Alves da. O Ministério Público e a concretização de direitos humanos. Salvador: Juspodivm, 2016.

SILVA, Virgílio Afonso da. O Judiciário e as políticas públicas: entre transformação social e obstáculo à realização dos direitos sociais. In: SOUZA NETO, Cláudio Pereira de; SARMENTO, Daniel (coord.). Direitos sociais: fundamentos, judicialização e direitos sociais em espécie. Rio de Janeiro: Lumen Juris, 2008, p. 587-599.

Derechos sociales como mandatos de optimización, su subjetivización y justiciabilidad: un análisis empírico. In: CLÉRICO, Laura et. al. (coord.). Derechos 
fundamentales, principios y argumentación: estudios sobre la teoría jurídica de Robert Alexy. Granada: Comares, 2011, p. 199-218.

Direitos Fundamentais: conteúdo essencial, restrições e eficácia. $2^{\underline{a}}$ ed. São Paulo: Malheiros, 2014.

SILVA, Virgílio Afonso da; MENDES, Conrado Hübner. Habermas e a jurisdição constitucional. In: NOBRE, Marcos; TERRA, Ricardo (org.). Direito e democracia: um guia de leitura de Habermas. São Paulo: Malheiros, 2008, p. 199-222.

SIMÕES, Edson. Tribunais de Contas: controle externo das contas públicas. São Paulo: Saraiva, 2014.

SOTO, Tarcisio Oviedo. El ombudsman como organismo de control de la Administración. Revista de Derecho, v. 62, no 196: 129-140, jul./dic. 1994.

SOUZA, Luciane Moessa de. Resolução de conflitos envolvendo o poder público: caminhos para uma consensualidade responsável e eficaz. In: GABBAY, Daniela Monteiro; TAKAHASHI, Bruno (coord.). Justiça Federal: inovações nos mecanismos consensuais de solução de conflitos. Brasília: Gazeta Jurídica, 2014, p. 189-207.

STRECK, Lenio Luiz. O papel da jurisdição constitucional na realização dos direitos sociais-fundamentais. In: SARLET, Ingo Wolfgang (org.). Direitos fundamentais sociais: estudos de direito constitucional, internacional e comparado. Rio de Janeiro: Renovar, 2003, p. 169-213.

TALAMINI, Eduardo. A (in)disponibilidade do interesse público: consequências processuais (composições em juízo, prerrogativas processuais, arbitragem, negócios processuais e ação monitória) - versão atualizada para o CPC/2015. Revista de Processo, v. 42, n. 264: 83-107, fev. 2017.

TONIN, Maurício Morais. Solução de controvérsias e poder público: negociação e arbitragem. Tese de Doutorado. Faculdade de Direito da Universidade de São Paulo, 2016. 
TUSHNET, Mark. Civil Rights and Social Rights: The Future of the Reconstruction Amendments. Loyola of Los Angeles Law Review, n. 25: 1207-1220, 1992. Disponível em http://heinonline.org/HOL/Page?handle=hein.journals/lla25\&start_page=1207\&coll ection=journals\&id=1231. Acesso em 25.10.2017.

. Taking the Constitution away from the Courts. New Jersey: Princeton University Press, 2000.

TWEEDY, John; HUNT, Alan. The Future of the Welfare State and Social Rights: Reflections on Habermas. Journal of Law and Society, v. 21, n. 3: 288-316, sep. 1994. Disponível em http://www.jstor.org/stable/1410737. Acesso em 04.04.2017.

UGGLA, Fredrik. The Ombudsman in Latin America. Journal of Latin American Studies, v. 36, n. 3: 423-450, aug. 2004. Disponível em: http://www.jstor.org/stable/3875987. Acesso em 04.04.2017.

VALDÉS, Daisy de Asper y. A instituição brasileira do "ombudsman": o papel do Ministério Público da União. Revista da Procuradoria-Geral da República, n. 1: 139-152, out./dez. 1992.

VENTURI, Elton. Transação de direitos indisponíveis? In: ZANETI JR., Hermes; CABRAL, Trícia Navarro Xavier (coord.). Justiça multiportas: mediação, conciliação, arbitragem e outros meios de solução adequada de conflitos. Salvador: Juspodivm, 2016, p. 405-429.

VERÍSSIMO, Marcos Paulo. A judicialização dos conflitos de justiça distributiva no Brasil: o processo judicial no pós-1988. Tese de Doutorado. Faculdade de Direito da Universidade de São Paulo, 2006.

VIANNA, Luiz Werneck; BURGOS, Marcelo. Revolução processual do direito e democracia progressiva. In: VIANNA, Luiz Werneck (org.). A democracia e os três Poderes no Brasil. Belo Horizonte: Editora UFMG; Rio de Janeiro: IUPERJ, FAPERJ, 2003, p. 337-491. 
VIANNA, Luiz Werneck; CARVALHO, Maria Alice Rezende de; MELO, Manuel Palacios Cunha; BURGOS, Marcelo Baumann. A judicialização da política e das relações sociais no Brasil. Rio de Janeiro: Revan, 1999.

WATANABE, Kazuo. Acesso à Justiça e sociedade moderna. In: GRINOVER, Ada Pellegrini; DINAMARCO, Cândido Rangel; WATANABE, Kazuo. Participação e processo. São Paulo: Revista dos Tribunais, 1988, p. 128-135.

YAMIN, Alicia Ely. The Future in the Mirror: Incorporating Strategies for the Defense and Promotion of Economic, Social, and Cultural Rights into the Mainstream Human Rights Agenda. Human Rights Quarterly, v. 27, n. 4: 12001244, nov. 2005. Disponível em: http://www.jstor.org/stable/20069832. Acesso em 04.04.2017.

ZENKNER, Marcelo. Ministério Público e efetividade do processo civil. São Paulo: Revista dos Tribunais, 2006. 